\title{
PLANTOGRAF V12 -New Transducer for Measurement Pressure Distribution Biomechanics and Technique
}

\author{
J. Volf\& J. Svatos\& V. Ryzhenko \\ Czech University of Life Sciences in Prague, Faculty of Engineering, Prague, Czech Republic
}

ABSTRACT: This paper describes the new Plantograf V12 that is new pressure distribution device. The
design of electrodes, properties of transducer, programmed software and using pressure distribution
measurements in technical application in automobile industry and technique is here showed. KEYWORD: Plantograf; conductive elastomer; electrodes; pressure distribution; tire.

\section{INTRODUCTION}

Plantograf V12 is a tactile transducer, which is able to pick up tactile information of a particular object and transfer this information into an electrical signal. This sensor is applied in the following applications: measurement of static and dynamic pressure distribution, human steps analysis, sitting position analysis, pressure distribution on a flat human foot and analysis of status of big joints (Volf, J. \& all. 1997), (Volf, J. \&Papežová, S. \& all. 2001).

Plantograf V12 has to fulfil the following conditions: the sensor cannot affect measured pressure distribution results, has to measure static and dynamic load, and has to have sufficient sensitivity and accuracy in each point of the sensor matrix for the given applications.

The contribution is focused on the description of the Plantograf V12 matrix construction, optimal electrode size determination in the point where a thin film made of conductive silicon elastomer is used to transfer load to electrical signal and SW properties.

\section{INTRODUCTION}

Construction of the Plantograf V12 was designed with regards to minimize influence on the matrix measuring points and maximization of the matrix point sensitivity. The matrix construction is displayed in a patent application

A part of the Plantograf V12 cross section is shown in Figure 1. Both electrodes are corroded onto one Cuflex film placed on the bottom part of the sensor matrix. Between the electrodes, changes of elastomer resistance are measured. (Trinkl, A. \& all. 2011).

Every electrode is covered with the conductive elastomer over its whole surface. The electrodes with these conductive elastomers are protected by non-conductive flexible material which protects the elastomers from mechanical wear (Volf, J. \& all. 2012).

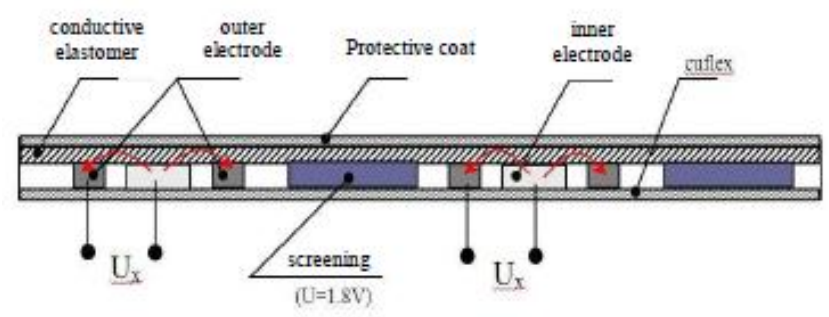

Figure 1. Cross section of Plantograf V12

It means that the current flow from the inner electrode flows through the conductive elastomer to the outer electrode.

The Plantograf V12 disposes by new electronic circles that are protects by a European patent application (Volf, J. \& all. 2009).

\section{OPTIMAL ELECTRODE SIZE DETERMINATIONTITLE, AUTHOR AND AFFILIATION FRAME}

A basic measurement task was carried out to determine the optimal electrode type for the application to give the sensors maximum measuring sensitivity.

A special modular system dedicated for tactile sensor measurement was used for measuring the 
points placed on the sensor matrix. This system measures the load applied on the matrix points in real time.

Simultaneously rate resistance is measured by means of SW and electronic circuits. Resistance can be in values between $0-255$.

The six different models of the sensor matrix were measured during determine testing process. The sensor matrix had following size:

The six different construction of the sensor matrix were measured during determination process. The sensor matrix had following size:

1. $\varnothing E=2 \mathrm{~mm}, \varnothing d=0,4 \mathrm{~mm}, M=0,1 \mathrm{~mm}-L H$

2. $\varnothing E=2 \mathrm{~mm}, \varnothing d=0,1 \mathrm{~mm}, M=0,1 \mathrm{~mm}-P H$

3. $\varnothing E=2,5 \mathrm{~mm}, \varnothing d=0,4 \mathrm{~mm}, M=0,25 \mathrm{~mm}-L D$

4. $\varnothing E=2,5 \mathrm{~mm}, \emptyset d=0,1 \mathrm{~mm}, M=0,25 \mathrm{~mm}-P D$

5. $\varnothing E=3,5 \mathrm{~mm}, \emptyset d=0,4 \mathrm{~mm}, M=0,25 \mathrm{~mm}$, separated measuring points $-O B$

6. $\varnothing E=3,5 \mathrm{~mm}, \emptyset d=0,4 \mathrm{~mm}, M=0,25 \mathrm{~mm}$, connected measuring points $-S B$

Varying model sizes are displayed in Figure 2.

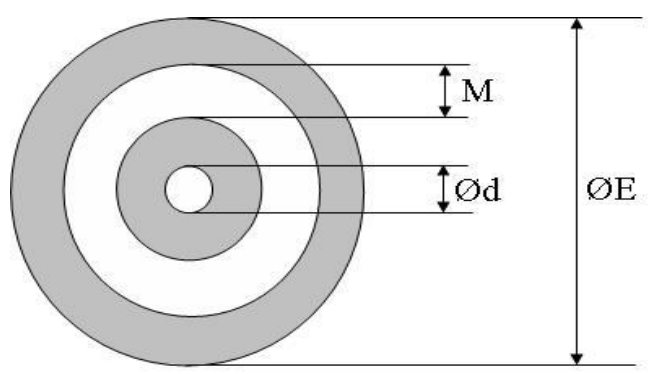

Figure 2. Sizes of Measured Electrodes

Construction numbers 5 and 6 have the same electrode size. Construction number 5 has the conductive elastomer only at the measuring spots. Construction number 6 has got the conductive elastomer over its whole surface of the sensor matrix. Three measurements were done on every model. Every point was measured three times in a range of $0,5 \mathrm{~N}-9,5 \mathrm{~N}$ (10 measurements) loads. Every point was measured tree times in range $0,5 \mathrm{~N}$ $-9,5 \mathrm{~N}$ (10 measurements) without any loads.

The average values from the measurements are shown in the Figure 3.

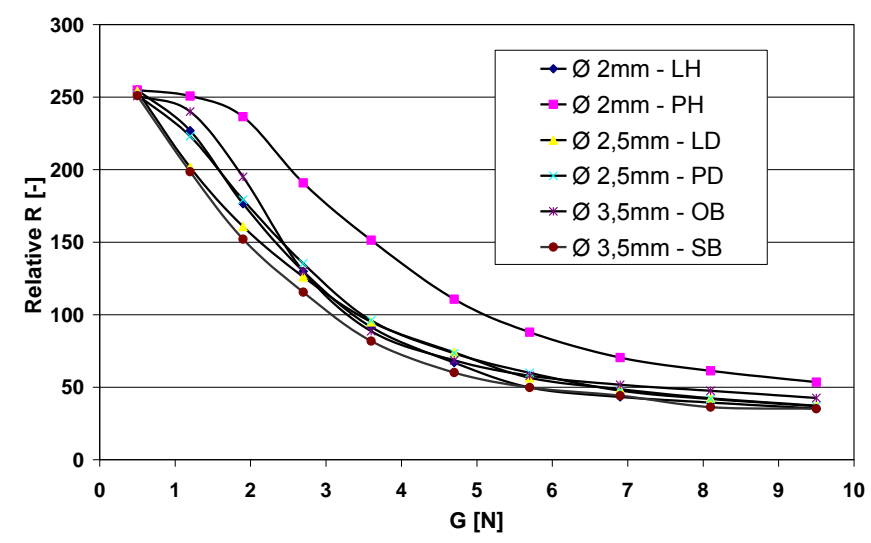

Figure 3 Measured values of different electrode types

\section{TECHNICAL PARAMETERS AND OUTPUT OF PLANTOGRAF V12}

For real construction were the best the electrodes type LD or SB. The electrodes of type LD were selected for the Plantograf V12 final construction. Figure 4 shows the Plantograf V12. These technical parameters were obtained:

$\begin{array}{ll}\text { Patient mass to } & 150 \mathrm{~kg} \\ \text { Rated pressure range } & 5-100 \mathrm{kPa} \\ \text { Permissible overload } & 1.4 \mathrm{MPa} \\ \text { Tire loading } & 3000 \mathrm{~kg} \\ \text { Permissible overload } & 14 \mathrm{MPa} \\ \text { Transducer active area } & 500 \times 500 \mathrm{~mm} \\ \text { Sensors number } & 16400 \mathrm{pcs} \\ \text { Sensor dimension diameter } & 2,5 \mathrm{~mm} \\ \text { Transducer supply voltages } & +5 \mathrm{~V} \\ \text { Digital output } & 256 \text { levels } \\ \text { Snap frequency } & 1 \mathrm{kHz}\end{array}$

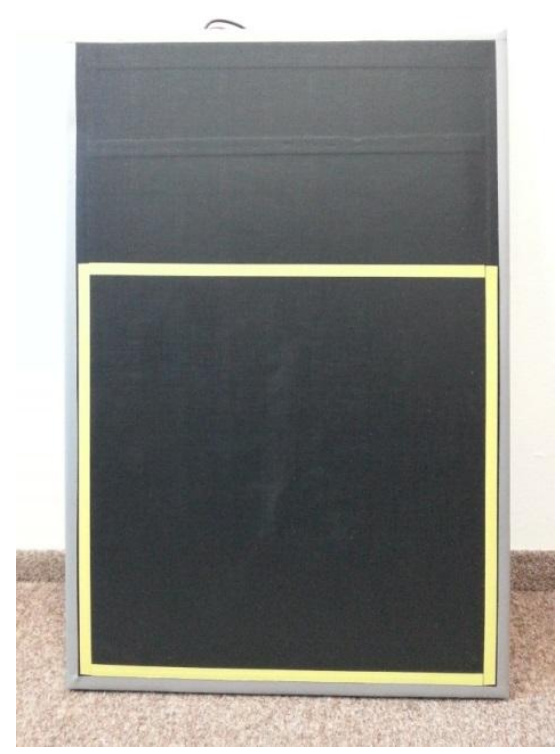

Figure 4. Plantograf V12

Figure 5 shows images of human sole by biomechanical application of Plantograf and Figure 6 shows images by technical application in automobile industry.
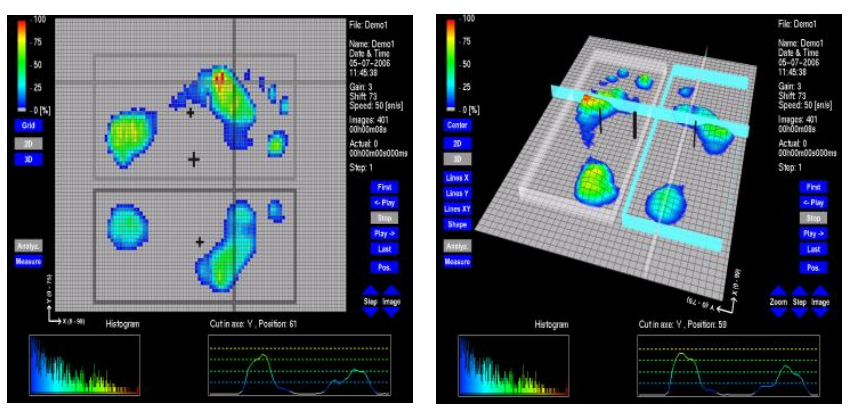

Figure 5. 2D and 3D images 

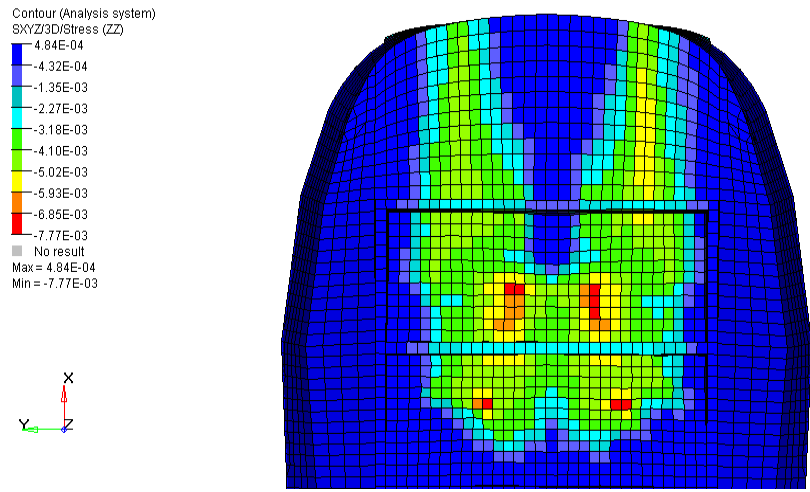

Figure 6. Use in automobile industry Pressure distribution on the seat of Skoda cars

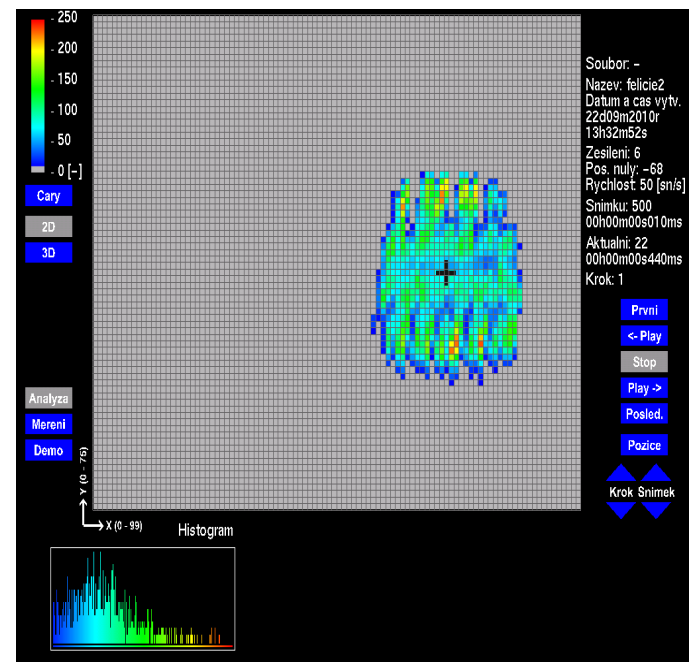

Figure 7. Pressure distribution between the tyre and road

\section{SW DESCRIPTION}

The device is established to measure pressure (the value of points) from the contact forces transducer, give its record and basic assessment. All already measured data can be reversely read to SW and processed (as if they were just measured), or they can be monitored and processed externally.

The programme is not created as a closed unit, it is a modular concept. SW is created by WIN 32 Microsoft NET C\# (DirectX graphic output). The user can easily create own (for example mathematical) blocks using so-called libraries.

The device can be easily run from a connected PC. During each measuring several parameters can be set independently (some parameters are significant for certain modes only).

- Measuring speed/obtaining the record. (Depends on the Measurement Mode.)

- Transducer Signal Gain. (0.5x, 1x, 1.5x, 2x, 3x, $4 x, 5 x)$. Suitable for the use of full range images or for restrictions when exceeding limits.

- Input Signal Zero Set. This property for example prevents the transfer of interference/noise into measured data. Or, conversely, it moves the recording limit to the area of noise in order to depict even the least load.

- Record Trigger Mode:

- Immediate from a PC

- external

- during transducer activation, e.g. by tread

- synchronization with other recording devices, e.g. video camera

All recorded data can be stored in several formats:

- Working DAT files. These can be read to SW reversely anytime and all application functionality can be used as if they were just measured. They can be later stored in a different format. The stored data maintain all settings and information set during the measuring.

- Text files TXT. Suitable for processing measured data using another programme (EXCEL, MATLAB...).

- BMP pictures. For later print, modifications and for the use in your own files.

- DivX or XviD video record can be created from the measured record.

Serviceable SW provides not only the monitoring and storage of the measured data; it also provides their basic processing. While monitoring, the following is possible:

- displaying any snap from a measured (recorded) course. The required snap can be set according to its time or as a number in its course.

- rotating the snaps following $\mathrm{X}$ and $\mathrm{Y}$ axis and their zooming.

- measuring the length of the selected points and their level.

- playing the record with selected speed in both directions.

- displaying the main pressure centre (centre of gravity - COP) for the snap.

- displaying record histogram.

- creating local/separate regions in the snap and displaying their pressure centres.

- creating your own horizontal and vertical cuts. Each cut can open a dialogue for replaying a record and observing progress in selected cuts.

- creating your own colour scale for display (pressure/colour). This can be used for instance for emphasising some pressure levels using a selected unique colour.

- From recorded values creating a DivX or XviD video record which can be played on any computer with Microsoft Windows OS.

- working with 2D and 3D visualization.

- rotating the picture arbitrarily, changing the height and displaying level lines.

exporting the measured data into EXCEL.

Besides the display, it allows mathematical processing: 
- For a selected cut it is possible to create a file record about the cut course in all (selected) snaps. The record may contain other cut data (minimum, maximum, average value, histogram...).

\section{CONCLUSION}

This paper described way of Plantograf V12 construction, its properties and obtained technical parameters.

The construction of the tactile transducer Plantograf V12 is the newest of the PlantografVxx line.

Measurement results show that sensor sensitivity varies with the used construction type of the sensor matrix. Construction type $\mathrm{PH}$ has got the lowest sensitivity (Fig.3). Construction type SB has got the highest sensitivity.

The results confirmed the possibility to use miniature sensors in a Plantograf system to measure the pressure between a subject (e.g. human sole, tire and etc) and transducer.

\section{ACKNOWLEDGEMENTS}

The measurements were carried out within the IGA project of the Faculty of Engineering, Czech University of Life Sciences in Prague, reg. no. IGA 31200/1312/3131, entitled "Experimental Research of Suitable Conductive Inks for Plantograf Measuring System and Electronic System Development".

\section{REFERENCES}

[1] Trinkl, A. \&Volf, J. \&Novák, M. \&Růžička, M. \&Vlček, J. 2011.Plantograf V09 and Optimal Size Determination Sensor Electrodes. The 15th World Multi-Conference on Systemics, Cybernetics and Informatics (WMSCI 2011), Orlando, Florida, USA, 2011. pp. 32-35. ISBN 978-1936338-30-6.

[2] Volf, J. \& Holy, S. \&Vlcek, J. 1997.Using of Tactile Transducer for Pressure Distribution Measurement on Sole, Sensor and Actuators A62. Physical, ELSEVIER SEQUOIA S.A., pp. 556-561, Lousanne, Switzerland 1997.

[3] Volf, J. \& Papežová, S. \&Vlček, J. \&Otáhal, J. \&Novák, P. \&Holý S. 2001.Transducer for Pressure Distribution Measurement and its Practical Tests. In.: The 5th World Multi-Conference on Systemics, Cybernetics and Informatics SCI 2001. Orlando 2001, Florida USA, p.575. ISBN 980-07-7555-2.

[4] Volf, J. \&Trinkl, A. \&Růžička, M. \&Novák, M. 2009.Optimal Size Determination of Tactile Sensor Plantograf V08 and its Electrodes.26th Symposium on Advances in Experimental Mechanics. Leoben, Austria 2009. ISBN: 978-3-902544-025

[5] Volf, J. \&Trinkl, A. \&Novák, M. \&Bílek, J. \&Prikner, P. \& Neuberger, P. 2012. Plantograf V12 with Optimal Size Determination Sensor Electrodes and its Using for Pressure Distribution Between Tire and Road. In: XX World Congress IMEKO, Busan, 2012, pp. 1-4, ISBN 978-89950000-5-2 95400. 